\title{
Novel aspects of platelet factor XIII function
}

\author{
Joanne L. Mitchell \& Nicola J. Mutch
}

Institute of Medical Sciences, University of Aberdeen, Aberdeen, UK.

Key words: factor XIII, platelets, fibrinolysis, $\alpha_{2}$-antiplasmin, fibrin

Word count main text: 1406

Word count abstract: 77

Nr of figures: 2

$\mathrm{Nr}$ of references: 63

Corresponding Author:

Dr Nicola J Mutch

School of Medicine \& Dentistry

Institute of Medical Sciences

Foresterhill

University of Aberdeen

Aberdeen

AB25 2ZD

UK

Email: n.j.mutch@abdn.ac.uk

Tel: +44 1224437492 


\begin{abstract}
Pools of factor XIII (FXIII) exist in the plasma and within the cytoplasm of hematopoietic cells, including platelets. The functions of the cellular form, FXIII-A, have been assumed to be intracellular in nature, as the protein lacks a signal sequence for its release. Mounting evidence now suggests that platelet FXIII-A modulates hemostasis by several different mechanisms. In this condensed review we discuss recent advances in our understanding of the novel intracellular and extracellular functions of platelet FXIII-A.
\end{abstract}




\section{Background}

Factor XIIIa (FXIIIa; E.C. 2.3.2.13) is a glutaminyl-peptide $\mathrm{Y}$-glutamyl transferase that functions to stabilize fibrin against mechanical stress and proteolytic degradation. FXIII circulates in plasma as a tetramer composed of two pairs of non-identical subunits; the A2 subunits, containing the active site and the carrier B2 subunits [1].

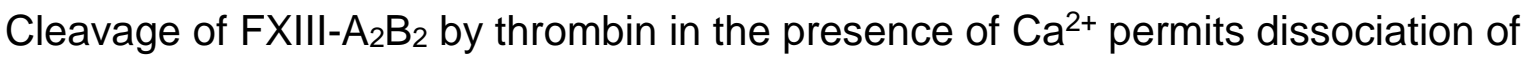
the carrier $B$ subunits and exposure of the active site cysteine generating an active transglutaminase enzyme, FXIIIa [2, 3]. FXIIIa is unique in its classification as a coagulation factor, as it is the only non-proteolytic enzyme within the cascade.

\section{Cross-linking of fibrin and inhibitors by FXIIIa}

Activated FXIII crosslinks substrates via formation of $\varepsilon$-( $\gamma$-glutamyl) lysyl isopeptide bonds [4]. Numerous factor XIII substrates have now been identified, including a number of platelet-derived proteins such as actin, glycoprotein $1 \mathrm{~b}$ and other cytoskeletal elements [5-10]. This review will centre on cross-linking of fibrin and inhibitors of fibrinolysis. The initial cross-links that form in fibrin arise rapidly between $y$-chains of neighbouring fibrin molecules [11] with subsequent high molecular weight polymers forming upon $\alpha$-chain cross-linking $[3,12]$. Cross-linking has a direct impact on the rheological properties of fibrin, enhancing clot rigidity and stabilizing against mechanical stress [13, 14]. FXIIla also cross-links several inhibitors of fibrinolysis to fibrin, namely $\alpha_{2}$-antiplasmin ( $\left.\alpha_{2} A P\right)$ [15], thrombin activatable fibrinolysis inhibitor [16] and plasminogen activator inhibitor-2 [17]. The influence of cross-linking on inhibition of fibrinolysis is difficult to visualise using conventional in vitro models, such as clot lysis. However, using a flow-based model we were able to demonstrate a direct effect of FXIIla in down-regulating thrombus lysis [18]. $\alpha_{2} \mathrm{AP}$ is the principal fast acting inhibitor of the fibrinolytic protease plasmin [19] and is cross-linked via GIn-2 to Lys-303 of the A $\alpha$ chain of fibrin(ogen) by FXIIIa [20]. Neutralization or deficiency of $\alpha_{2}$ AP dramatically impacts the susceptibility of thrombi to fibrinolysis $[15,21,22]$. Using flow we revealed that the antifibrinolytic function of FXIIIa is exclusively mediated via cross-linking of $\alpha_{2} A P$ to fibrin, with thrombi that lack either FXIII or $\alpha_{2} A P$ lysing at strikingly similar rates [23]. 


\section{Cellular FXIII-A}

FXIII exists in a cellular form (FXIII-A) within the cytoplasm of several haematopoietic cells including platelets [1, 24-29] megakaryocytes [30], monocytes [31, 32], circulating [33] and tissue macrophages [32]. Platelets contain an abundance of FXIII [34] predominantly within their cytoplasm, as a homodimer of FXIII-A [26, 27], however a small pool of the $\mathrm{A}_{2} \mathrm{~B}_{2}$ form is reported to exist within $\alpha$-granules [26, 35]. The source of $\alpha$-granule FXIII is plasmatic, as the $A_{2} B_{2}$ form circulates bound to fibrinogen and both are simultaneously endocytosed by platelets [35]. Early studies indicated that platelet FXIII-A is retained in the cytoplasm following activation and is not detectable in the platelet secretome [36]. FXIII-A does not contain an identifiable endoplasmic reticulum (ER) signalling sequence and is excluded from the ER-Golgi pathway in nucleated cells [37]. However, it has been found to be directed toward the plasma membrane in association with Golgi vesicles in monocyte-macrophages [38]. Due to the lack of ER-leader sequence FXIII-A cannot be targeted to $\alpha$ granules in nascent platelets during de novo synthesis in megakaryocytes. This has led to the assumption that the functions of platelet FXIII-A are intracellular and distinct from the role of the plasma $A_{2} B_{2}$ form of FXIII in hemostasis.

\section{Intracellular roles of platelet FXIII-A}

Activation of platelets by conventional agonists generates a rapid spike in intracellular $\mathrm{Ca}^{2+}$ [39], where concentrations above $2 \mathrm{mM}$ [40] enable non-proteolytic activation of FXIII-A [41]. Platelet FXIII-A has been implicated in several intracellular-mediated processes, including clot retraction. This dynamic process involves the reorganisation of proteins and structures at intra- and extracellular level and bidirectional signalling via the integrin, $\alpha$ llb $\beta 3$. Initially, inside-out signalling induces a conformational change in $\alpha$ llb $\beta 3$ allowing it to bind extracellular fibrin(ogen) [42]. Once in place the ligand triggers allbß3-mediated outside-in signalling [43] which connects to the actin cytoskeleton via talin [44]. The actin 
cytoskeleton then effectively acts as a winch to reel in the fibrin coupled to the extracellular portion of the receptor via platelet pseudopodia. Plasma FXIII also facilitates clot retraction by cross-linking extracellular fibrin, thereby increasing network rigidity, and by enhancing platelet spreading [45]. Clot retraction is significantly impaired in the absence of platelet FXIII-A transglutaminase activity [46, 47]. Platelet FXIII-A also cross-links intracellular cytoskeletal proteins [6-10] and regulates reorganisation of the activated platelet cytoskeleton and $\alpha \mathrm{llb} \beta 3$ via sphingomyelin-rich lipid rafts, which act as the axis between intracellular and extracellular clot retraction mechanisms [46].

During thrombus formation different subpopulations of platelets arise [48] which display distinct phenotypic characteristics and play diverse roles within the microenvironment of the thrombus. Adherent platelets, with activated allb $\beta 3$, facilitate platelet-platelet interaction and binding to fibrin thereby augmenting thrombus stability [48]. Phosphatidylserine (PS)-exposing procoagulant platelets promote thrombin generation and further fibrin formation [49]. Platelet FXIII-A and calpain have been implicated in the adhesive capacity of $\alpha$ llb $\beta 3$ in procoagulant platelets thereby regulating thrombus size [50]. Formation of the highly procoagulant 'coated' platelets is also regulated by transglutaminase activity, which cross-links $\alpha$ granule proteins, such as platelet factor $\mathrm{V}$, to serotonin on the activated platelet surface [51, 52]. Jobe et al [53] demonstrated that FXIII was dispensable for coated platelet formation in mice. Interestingly, these FXIIIA-/- mice demonstrated increased transglutaminase activity in platelet lysates, suggestive of a compensatory mechanism by another transglutaminase. Recent findings confirmed the contribution of tranglutaminase and highlighted a role for the integrin $\alpha \operatorname{lb} \beta 3$ in coated platelet formation and in subsequent platelet-dependent fibrin formation [54].

\section{Extracellular functions of platelet FXIII-A}

Early studies on the antifibrinolytic function of platelet FXIII-A identified that platelets mediated stabilization of clots [55], induced high molecular weight $\gamma$-dimer and $\alpha$ polymer formation [55-59] and cross-linked $\alpha_{2} A P$ to fibrin $[56,57]$. Despite these studies implicating platelet FXIII-A in extracellular hemostasis events there was no direct evidence illustrating its release from platelets. Our recent work has shown that platelet FXIII-A is undetectable in the platelet secretome, as previously reported [36], 
but is externalized onto the outer membrane of activated platelets [60]. Intriguingly, the distribution of FXIII-A on the activated platelet membrane depends on the subpopulation of platelets; with PS-negative, adherent platelets displaying a diffuse distribution, while PS-positive, procoagulant platelets expose FXIII-A in a single protruding 'cap' (Figure 1) [60]. These 'caps' have previously been shown to bind fibrinogen [61] and we have shown that they harbour other proteins including plasminogen and PAI-1 [62]. The reduction in the adhesive ability of $\alpha$ llb $\beta 3$ by FXIIIA [50] combined with the clustering of fibrinolytic proteins in the 'caps' of these procoagulant platelets suggest they may function in regulating thrombus stability. We found that thrombi formed from FXIII-deficient plasma were stabilized by the addition of platelets in a transglutaminase-dependent manner [60]. In order to protect against fibrinolysis functional $\alpha_{2} \mathrm{AP}$ was required, indicating that platelet FXIII-A actively participates in extracellular cross-linking reactions [60].

Surface exposure and cross-linking by platelet FXIII-A was only evident following platelet activation and coincided with translocation from the cytoplasm to the outer leaflet of the membrane [60]. The exact signalling mechanisms involved are still to be defined, but it is likely that the previously described interactions of FXIII-A with intracellular clot retraction machinery [6-10], lipid rafts [46] and $\alpha$ llb $\beta 3$ are crucial to its externalization upon platelet activation (Figure 2). FXIII-A activity was also evident with thrombin receptor activation peptide 6 (TRAP-6)-mediated platelet activation, confirming that activation from the protransglutaminase to functional transglutaminase does not require thrombin and arises from the spike in intracellular $\mathrm{Ca}^{2+}$ upon activation. Interestingly, inhibition of fibrin polymerisation with Gly-ProArg-Pro, or activation of platelets by TRAP- 6 in place of thrombin reduced the number of FXIII-A-positive platelets. These data imply that platelet-bound fibrin participates in the retention of FXIII-A and possibly serves as an anchor-point for transfer of FXIII-A into the adjacent fibrin network allowing participation in extracellular cross-linking reactions [60]. It has been shown that FXIII-A binds to the $\alpha \mathrm{C}$ domain (residues 389-402) of fibrin(ogen) via both its active site [63] and its activation peptide cleft thereby promoting crosslinking of fibrin and $\alpha_{2} A P$ [64]. It is plausible that upon platelet activation FXIII-A will bind to platelet-bound fibrin via these two sites. In accordance with this the fibrin network immediately adjacent to the surface of activated platelets is extremely resistant to fibrinolysis [62, 65-68]. 
The antifibrinolytic function of platelet FXIII-A may be central in stabilizing thrombi in certain situations, such as during surgery when plasma FXIII- $\mathrm{A}_{2} \mathrm{~B}_{2}$ levels rapidly decline [69] or following cardiopulmonary bypass with extracorporeal circuit. Acquired FXIII deficiency can also occur in the case of major trauma where plasma FXIII-A $\mathrm{A}_{2} \mathrm{~B}_{2}$ levels deplete to around $30-35 \%$ of normal [70]. FXIII-B subunit deficiency leads to dramatic reduction in FXIII-A concentration in plasma, due to its instability [71-73], however platelet FXIII-A levels are normal [72, 74]. FXIII-B deficiency is less severe than FXIII-A deficiency $[71,75]$ which is attributed to remaining circulating FXIII-A in plasma. Our results indicate that platelet FXIII-A may contribute to thrombus stabilization in these situations. We show that when plasma FXIII-A $\mathrm{A}_{2} \mathrm{~B}_{2}$ is below $20 \%$ of normal the antifibrinolytic effect of platelet FXIII-A becomes apparent [60].

\section{Concluding remarks}

Clearly the role of platelet FXIII-A has been markedly underestimated with a mounting body of evidence highlighting its importance in modulating platelet phenotype [50-52], facilitating the intracellular elements of clot retraction $[46,47]$ and mediating extracellular cross-linking reactions [60]. These reports illustrate that FXIII-A has diverse and crucial functions in thrombus formation and stability. Further work is required to tease out the importance of platelet FXIII-A in relation to plasmaderived FXIII and whether these enzymes play functionally distinct but overlapping roles in hemostasis. There are also multiple questions related to the signalling events involved in the externalisation of cytoplasmic FXIII-A on the stimulated platelet membrane and its ability to actively diffuse into the surrounding fibrin network; as suggested by its ability to cross-link extracellular substrates (Figure 2). These observations and insights into the functions of platelet FXIII-A underscore the seamless transition between intracellular and extracellular events that modulate thrombus formation and stability in vivo. 


\section{Acknowledgments}

The study was supported by grants FS/11/2/28579 (N.J.M.) from the British Heart Foundation and the University of Aberdeen Development Trust.

\section{Conflict of Interest Disclosures}

The authors have no conflicts to declare. 


\section{References}

[1] Schwartz ML, Pizzo SV, Hill RL, McKee PA. The subunit structures of human plasma and platelet factor XIII (fibrin-stabilizing factor). J Biol Chem. 1971;246:58514.

[2] Lorand L, Konishi K. Activation of the Fibrin Stabilizing Factor of Plasma by Thrombin. Arch Biochem Biophys. 1964;105:58-67.

[3] Schwartz ML, Pizzo SV, Hill RL, McKee PA. Human Factor XIII from plasma and platelets. Molecular weights, subunit structures, proteolytic activation, and crosslinking of fibrinogen and fibrin. J Biol Chem. 1973;248:1395-407.

[4] Pisano JJ, Finlayson JS, Peyton MP. [Cross-link in fibrin polymerized by factor 13: epsilon-(gamma-glutamyl)lysine]. Science. 1968;160:892-3.

[5] Nikolajsen CL, Dyrlund TF, Poulsen ET, Enghild JJ, Scavenius C. Coagulation factor XIIla substrates in human plasma: identification and incorporation into the clot. J Biol Chem. 2014;289:6526-34.

[6] Cohen I, Young-Bandala L, Blankenberg TA, Siefring GE, Jr., Bruner-Lorand J. Fibrinoligase-catalyzed cross-linking of myosin from platelet and skeletal muscle. Arch Biochem Biophys. 1979;192:100-11.

[7] Cohen I, Blankenberg TA, Borden D, Kahn DR, Veis A. Factor XIIla-catalyzed cross-linking of platelet and muscle actin. Regulation by nucleotides. Biochim Biophys Acta. 1980;628:365-75.

[8] Cohen I, Glaser T, Veis A, Bruner-Lorand J. Ca2+-dependent cross-linking processes in human platelets. Biochim Biophys Acta. 1981;676:137-47.

[9] Asijee GM, Muszbek L, Kappelmayer J, Polgar J, Horvath A, Sturk A. Platelet vinculin: a substrate of activated factor XIII. Biochim Biophys Acta. 1988;954:303-8. [10] Serrano K, Devine DV. Intracellular factor XIII crosslinks platelet cytoskeletal elements upon platelet activation. Thromb Haemost. 2002;88:315-20.

[11] Weisel JW, Francis CW, Nagaswami C, Marder VJ. Determination of the topology of factor XIIIa-induced fibrin gamma-chain cross-links by electron microscopy of ligated fragments. J Biol Chem. 1993;268:26618-24.

[12] McKee PA, Mattock P, Hill RL. Subunit structure of human fibrinogen, soluble fibrin, and cross-linked insoluble fibrin. Proc Natl Acad Sci U S A. 1970;66:738-44. [13] Mockros LF, Roberts WW, Lorand L. Viscoelastic properties of ligation-inhibited fibrin clots. Biophys Chem. 1974;2:164-9.

[14] Shen L, Lorand L. Contribution of fibrin stabilization to clot strength. Supplementation of factor XIII-deficient plasma with the purified zymogen. J Clin Invest. 1983;71:1336-41.

[15] Sakata Y, Aoki N. Cross-linking of alpha 2-plasmin inhibitor to fibrin by fibrinstabilizing factor. J Clin Invest. 1980;65:290-7.

[16] Valnickova Z, Enghild JJ. Human procarboxypeptidase $U$, or thrombin-activable fibrinolysis inhibitor, is a substrate for transglutaminases. Evidence for transglutaminase-catalyzed cross-linking to fibrin. J Biol Chem. 1998;273:27220-4. [17] Ritchie H, Robbie LA, Kinghorn S, Exley R, Booth NA. Monocyte plasminogen activator inhibitor 2 (PAI-2) inhibits u-PA-mediated fibrin clot lysis and is cross-linked to fibrin. Thromb Haemost. 1999;81:96-103.

[18] Mutch NJ, Koikkalainen JS, Fraser SR, Duthie KM, Griffin M, Mitchell J, et al. Model thrombi formed under flow reveal the role of factor XIII-mediated cross-linking in resistance to fibrinolysis. J Thromb Haemost. 2010;8:2017-24. 
[19] Moroi M, Aoki N. Isolation and characterization of alpha2-plasmin inhibitor from human plasma. A novel proteinase inhibitor which inhibits activator-induced clot lysis. J Biol Chem. 1976;251:5956-65.

[20] Kimura S, Aoki N. Cross-linking site in fibrinogen for alpha 2-plasmin inhibitor. J Biol Chem. 1986;261:15591-5.

[21] Fraser SR, Booth NA, Mutch NJ. The antifibrinolytic function of factor XIII is exclusively expressed through \{alpha\}2-antiplasmin cross-linking. Blood. 2011.

[22] Sakata Y, Aoki N. Significance of cross-linking of alpha 2-plasmin inhibitor to fibrin in inhibition of fibrinolysis and in hemostasis. J Clin Invest. 1982;69:536-42.

[23] Fraser SR, Booth NA, Mutch NJ. The antifibrinolytic function of factor XIII is exclusively expressed through alpha-antiplasmin cross-linking. Blood.

2011;117:6371-4.

[24] Buluk K. [An unknown action of blood platelets; preliminary communication]. Pol Tyg Lek (Wars). 1955;10:191.

[25] Luscher EF. [Fibrin-stabilizing factor from thrombocytes]. Schweiz Med Wochenschr. 1957;87:1220-1.

[26] Lopaciuk S, Lovette KM, McDonagh J, Chuang HY, McDonagh. Subcellular distribution of fibrinogen and factor XIII in human blood platelets. Thromb Res.

1976;8:453-65.

[27] Sixma JJ, van den Berg A, Schiphorst M, Geuze HJ, McDonagh J. Immunocytochemical localization of albumin and factor XIII in thin cryo sections of human blood platelets. Thromb Haemost. 1984;51:388-91.

[28] Nurden AT, Kunicki TJ, Dupuis D, Soria C, Caen JP. Specific protein and glycoprotein deficiencies in platelets isolated from two patients with the gray platelet syndrome. Blood. 1982;59:709-18.

[29] Zhu Y, Tassi L, Lane W, Mendelsohn ME. Specific binding of the transglutaminase, platelet factor XIII, to HSP27. J Biol Chem. 1994;269:22379-84. [30] Kiesselbach TH, Wagner RH. Demonstration of factor XIII in human megakaryocytes by a fluorescent antibody technique. Ann N Y Acad Sci. 1972;202:318-28.

[31] Muszbek L, Adany R, Szegedi G, Polgar J, Kavai M. Factor XIII of blood coagulation in human monocytes. Thromb Res. 1985;37:401-10.

[32] Henriksson P, Becker S, Lynch G, McDonagh J. Identification of intracellular factor XIII in human monocytes and macrophages. J Clin Invest. 1985;76:528-34. [33] Adany R, Belkin A, Vasilevskaya T, Muszbek L. Identification of blood coagulation factor XIII in human peritoneal macrophages. Eur J Cell Biol. 1985;38:171-3.

[34] Katona EE, Ajzner E, Toth K, Karpati L, Muszbek L. Enzyme-linked immunosorbent assay for the determination of blood coagulation factor XIII A-subunit in plasma and in cell lysates. J Immunol Methods. 2001;258:127-35.

[35] Marx G, Korner G, Mou X, Gorodetsky R. Packaging zinc, fibrinogen, and factor XIII in platelet alpha-granules. J Cell Physiol. 1993;156:437-42.

[36] Joist $\mathrm{JH}$, Niewiarowski S. Retention of platelet fibrin stabilizing factor during the platelet release reaction and clot retraction. Thromb Diath Haemorrh. 1973;29:67983.

[37] Kaetsu H, Hashiguchi T, Foster D, Ichinose A. Expression and release of the a and b subunits for human coagulation factor XIII in baby hamster kidney (BHK) cells. J Biochem. 1996;119:961-9.

[38] Cordell PA, Kile BT, Standeven KF, Josefsson EC, Pease RJ, Grant PJ. Association of coagulation factor XIII-A with Golgi proteins within monocyte- 
macrophages: implications for subcellular trafficking and secretion. Blood. 2010;115:2674-81.

[39] Siess W. Molecular mechanisms of platelet activation. Physiol Rev. 1989;69:58178.

[40] Kristiansen GK, Andersen MD. Reversible activation of cellular factor XIII by calcium. J Biol Chem. 2011;286:9833-9.

[41] Muszbek L, Polgar J, Boda Z. Platelet factor XIII becomes active without the release of activation peptide during platelet activation. Thromb Haemost. 1993;69:282-5.

[42] Ginsberg MH, Du X, Plow EF. Inside-out integrin signalling. Curr Opin Cell Biol. 1992;4:766-71.

[43] Shattil SJ. Signaling through platelet integrin alpha Ilb beta 3: inside-out, outside-in, and sideways. Thromb Haemost. 1999;82:318-25.

[44] Knezevic I, Leisner TM, Lam SC. Direct binding of the platelet integrin alphallbbeta3 (GPIIb-IIla) to talin. Evidence that interaction is mediated through the cytoplasmic domains of both alphallb and beta3. J Biol Chem. 1996;271:16416-21. [45] Cohen I, Gerrard JM, White JG. Ultrastructure of clots during isometric contraction. J Cell Biol. 1982;93:775-87.

[46] Kasahara K, Kaneda M, Miki T, lida K, Sekino-Suzuki N, Kawashima I, et al. Clot retraction is mediated by factor XIII-dependent fibrin-alphallbbeta3-myosin axis in platelet sphingomyelin-rich membrane rafts. Blood. 2013;122:3340-8.

[47] Kasahara K, Souri M, Kaneda M, Miki T, Yamamoto N, Ichinose A. Impaired clot retraction in factor XIII A subunit-deficient mice. Blood. 2010;115:1277-9.

[48] Munnix IC, Kuijpers MJ, Auger J, Thomassen CM, Panizzi P, van Zandvoort MA, et al. Segregation of platelet aggregatory and procoagulant microdomains in thrombus formation: regulation by transient integrin activation. Arterioscler Thromb Vasc Biol. 2007;27:2484-90.

[49] Bevers EM, Comfurius P, van Rijn JL, Hemker HC, Zwaal RF. Generation of prothrombin-converting activity and the exposure of phosphatidylserine at the outer surface of platelets. Eur J Biochem. 1982;122:429-36.

[50] Kulkarni S, Jackson SP. Platelet factor XIII and calpain negatively regulate integrin alphallbbeta3 adhesive function and thrombus growth. J Biol Chem. 2004;279:30697-706.

[51] Dale GL, Friese P, Batar P, Hamilton SF, Reed GL, Jackson KW, et al. Stimulated platelets use serotonin to enhance their retention of procoagulant proteins on the cell surface. Nature. 2002;415:175-9.

[52] Szasz R, Dale GL. Thrombospondin and fibrinogen bind serotonin-derivatized proteins on COAT-platelets. Blood. 2002;100:2827-31.

[53] Jobe SM, Leo L, Eastvold JS, Dickneite G, Ratliff TL, Lentz SR, et al. Role of FcRgamma and factor XIIIA in coated platelet formation. Blood. 2005;106:4146-51. [54] Mattheij NJ, Swieringa F, Mastenbroek TG, Berny-Lang MA, May F, Baaten CC, et al. Coated platelets function in platelet-dependent fibrin formation via integrin alphallbbeta3 and transglutaminase factor XIII. Haematologica. 2015.

[55] Reed GL, Matsueda GR, Haber E. Platelet factor XIII increases the fibrinolytic resistance of platelet-rich clots by accelerating the crosslinking of alpha 2antiplasmin to fibrin. Thromb Haemost. 1992;68:315-20.

[56] Reed GL, Matsueda GR, Haber E. Fibrin-fibrin and alpha 2-antiplasmin-fibrin cross-linking by platelet factor XIII increases the resistance of platelet clots to fibrinolysis. Trans Assoc Am Physicians. 1991;104:21-8. 
[57] Hevessy Z, Haramura G, Boda Z, Udvardy M, Muszbek L. Promotion of the crosslinking of fibrin and alpha 2-antiplasmin by platelets. Thromb Haemost. 1996;75:161-7.

[58] Francis CW, Marder VJ. Rapid formation of large molecular weight alphapolymers in cross-linked fibrin induced by high factor XIII concentrations. Role of platelet factor XIII. J Clin Invest. 1987;80:1459-65.

[59] Rubens FD, Perry DW, Hatton MW, Bishop PD, Packham MA, KinloughRathbone RL. Platelet accumulation on fibrin-coated polyethylene: role of platelet activation and factor XIII. Thromb Haemost. 1995;73:850-6.

[60] Mitchell JL, Lionikiene AS, Fraser SR, Whyte CS, Booth NA, Mutch NJ. Functional factor XIII-A is exposed on the stimulated platelet surface. Blood. 2014;124:3982-90.

[61] Abaeva AA, Canault M, Kotova YN, Obydennyy SI, Yakimenko AO, Podoplelova NA, et al. Procoagulant platelets form an alpha-granule protein-covered "cap" on their surface that promotes their attachment to aggregates. J Biol Chem. 2013;288:29621-32.

[62] Whyte CS, Swieringa F, Mastenbroek TG, Lionikiene AS, Lance MD, van der Meijden PE, et al. Plasminogen associates with phosphatidylserine-exposing platelets and contributes to thrombus lysis under flow. Blood. 2015;125:2568-78. [63] Smith KA, Adamson PJ, Pease RJ, Brown JM, Balmforth AJ, Cordell PA, et al. Interactions between factor $\mathrm{XIII}$ and the alphaC region of fibrinogen. Blood. 2011;117:3460-8.

[64] Smith KA, Pease RJ, Avery CA, Brown JM, Adamson PJ, Cooke EJ, et al. The activation peptide cleft exposed by thrombin cleavage of FXIII-A(2) contains a recognition site for the fibrinogen alpha chain. Blood. 2013;121:2117-26.

[65] Collet JP, Montalescot G, Lesty C, Weisel JW. A structural and dynamic investigation of the facilitating effect of glycoprotein IIb/IIIa inhibitors in dissolving platelet-rich clots. Circ Res. 2002;90:428-34.

[66] Collet JP, Montalescot G, Lesty C, Mishal Z, Soria J, Choussat R, et al. Effects of Abciximab on the architecture of platelet-rich clots in patients with acute myocardial infarction undergoing primary coronary intervention. Circulation. 2001;103:2328-31.

[67] Collet JP, Montalescot G, Lesty C, Soria J, Mishal Z, Thomas D, et al. Disaggregation of in vitro preformed platelet-rich clots by abciximab increases fibrin exposure and promotes fibrinolysis. Arterioscler Thromb Vasc Biol. 2001;21:142-8. [68] Shenkman B, Einav Y, Livnat T, Budnik I, Martinowitz U. In vitro evaluation of clot quality and stability in a model of severe thrombocytopenia: effect of fibrinogen, factor XIII and thrombin-activatable fibrinolysis inhibitor. Blood Transfus. 2014;12:7884.

[69] Letheby BA, Davis RB, Larsen AE. The effect of major surgical procedures on plasma and platelet levels of Factor XIII. Thromb Diath Haemorrh. 1974;31:20-9. [70] Janning M, Holstein K, Spath B, Schnabel C, Bannas P, Bokemeyer C, et al. Relevant bleeding diathesis due to acquired factor XIII deficiency. Hamostaseologie. 2013;33 Suppl 1:S50-4.

[71] Saito M, Asakura H, Yoshida T, Ito K, Okafuji K, Matsuda T. A familial factor XIII subunit B deficiency. Br J Haematol. 1990;74:290-4.

[72] Izumi T, Hashiguchi T, Castaman G, Tosetto A, Rodeghiero F, Girolami A, et al. Type I factor XIII deficiency is caused by a genetic defect of its $b$ subunit: insertion of triplet AAC in exon III leads to premature termination in the second Sushi domain.

Blood. 1996;87:2769-74. 
[73] Koseki S, Souri M, Koga S, Yamakawa M, Shichishima T, Maruyama Y, et al. Truncated mutant B subunit for factor XIII causes its deficiency due to impaired intracellular transportation. Blood. 2001;97:2667-72.

[74] Ajzner E, Schlammadinger A, Kerenyi A, Bereczky Z, Katona E, Haramura G, et al. Severe bleeding complications caused by an autoantibody against the $B$ subunit of plasma factor XIII: a novel form of acquired factor XIII deficiency. Blood. 2009;113:723-5.

[75] Souri M, Koseki-Kuno S, Takeda N, Degen JL, Ichinose A. Administration of factor XIII B subunit increased plasma factor XIII A subunit levels in factor XIII B subunit knock-out mice. Int J Hematol. 2008;87:60-8. 


\section{Figure Legends}

\section{Figure 1: Activated platelets expose FXIII-A on their membrane surface.}

Washed platelets $\left(5 \times 10^{7} / \mathrm{ml}\right)$ stained using FITC-labelled anti-FXIII-A antibody (green) and Alexa-fluor ${ }^{\circ} 647$ Annexin-V to detect phosphatidylserine (red). Top panel - PS and FXIII-A co-expressing platelets stimulated by $20 \mu \mathrm{g} / \mathrm{ml}$ collagen/ 20 $\mu \mathrm{M}$ TRAP-6 or $20 \mu \mathrm{g} / \mathrm{ml}$ collagen /100 nM thrombin. Bottom Panel - PS-negative platelets stimulated with $20 \mu \mathrm{g} / \mathrm{ml}$ collagen/ $20 \mu \mathrm{M}$ TRAP-6 or $20 \mu \mathrm{g} / \mathrm{ml}$ collagen /100 $\mathrm{nM}$ thrombin. Scale bars represent $5 \mu \mathrm{M}$. Representative experiments of $n=4$. Images obtained by a Zeiss LSM710 confocal microscope with $63 \times 1.40$ oil immersion objective and analyzed using Zen 2012 software [60].

Figure 2: Schematic representation of interactions between platelets and FXIII.

Platelet activation results in the polymerization of intracellular actin and induces conformational changes in integrin $\alpha$ llb $\beta 3$ mediated via inside-out signalling.

Fibrin(ogen) is then able to bind $\alpha \mathrm{llb} \beta 3$ and outside-in signalling allows the binding of $\alpha \operatorname{llb} \beta 3$ to polymerised actin via talin. Platelet contractile machinery then pulls on the fibrin network via platelet pseudopods resulting in the compaction of the clot and extrusion of excess non-cross-linked material. Platelet FXIII-A plays a major role in the intracellular facilitation of clot retraction by cross-linking cytoskeletal proteins and facilitating reorganisation of the $\alpha \operatorname{llb} \beta 3$ and the platelet cytoskeleton via lipid rafts. Plasma FXIII enhances clot retraction extracellularly by cross-linking fibrin thereby providing further rigidity to the network and allowing enhanced platelet spreading. 

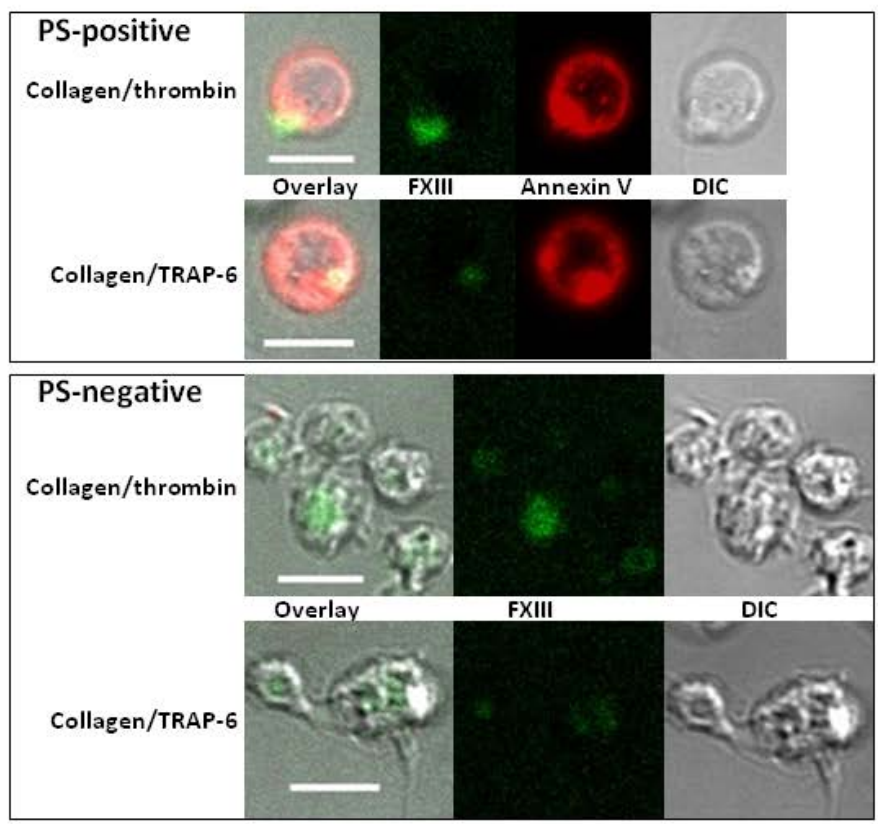


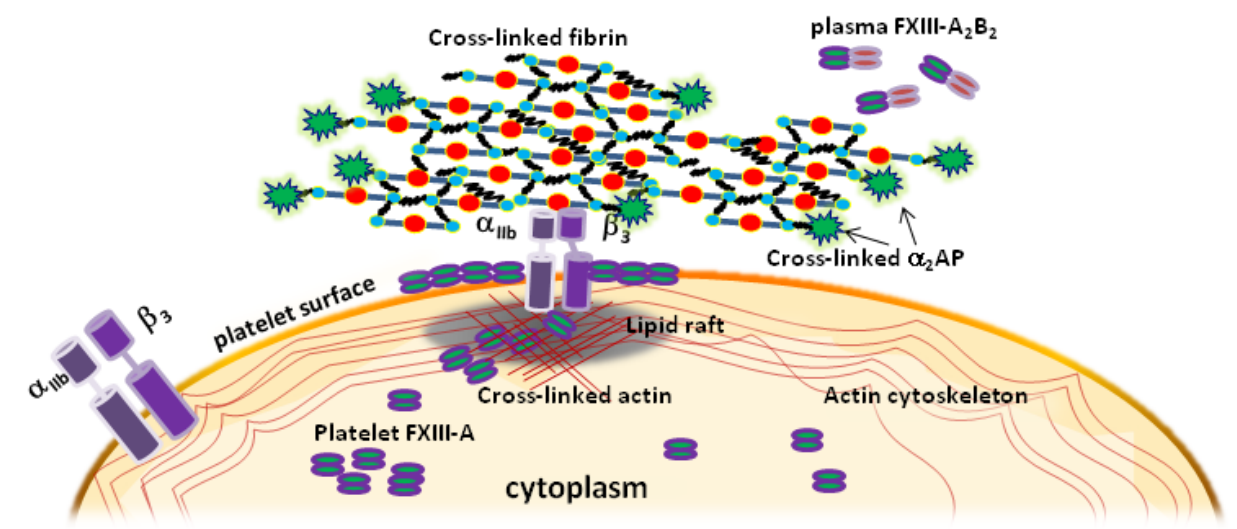

